\title{
Body Mass Index and Semen Quality in Partners of Infertile Couples
}

\author{
TANZEEM SABINA CHOWDHURY' ${ }^{1}$, TACHOWDHURY²
}

\begin{abstract}
:
Background: Obesity has almost doubled worldwide in the last 50 years and a great portion of these obese population are young adults. It has been proved that increased body weight has a negative correlation with female fertility. Recent studies show there has been decreasing semen quality with concurrent increase in BMI of the male partner. The aim of this study was to investigate the effect of obesity on sperm parameters among the male partners of the infertile couples from an infertility management center in Dhaka, Bangladesh.

Methods: A cross sectional study was carried out in Infertility Management Center, a tertiary center for infertility management and IVF in Dhaka, Bangladesh from August to October 2016. A total of 225 men presented for infertility evaluation during this period underwent BMI calculation and semen analysis.

Result: Out of 225 male partners, about two third (65.8\%) belonged to age 31 to 40 years.Majority (44.4\%) of the patients were overweight $\left(25-29.9 \mathrm{~kg} / \mathrm{m}^{2}\right)$. The mean total sperm count was found to be $54.4+53.2 \mathrm{million} / \mathrm{mL}$ with a range from 0 to $280 \mathrm{million} / \mathrm{m}$. The mean total motility of sperms was found to be $36.8+23.4$ percent with a range from 0 to 80 percent. The mean normal morphology was found to be $42.0+22.1 \%$ with a range of 0 to 80 percent. Regression analysis showed no correlation ( $r=0.003 ; p=0.966)$ between $B M I$ and total sperm concentration but showed negative correlation with total motility $(r=0.073 ; p=0.0277)$ and morphology of sperm $(r=0.088 ; p=0.186)$.

Conclusion: There was a negative correlation between sperm motility and morphology with higher BMI among male partners of couples seeking fertility treatment. So, male partners along with their female counterparts should be counseled about the importance of maintaining an ideal BMI for better fertility outcome.
\end{abstract}

Key words: Male infertility, Semen quality, BMI, Obesity

\section{Introduction:}

Obesity is one of the leading public health concerns in modernized society due to altered food habit and sedentary lifestyle among adult men and women. Studies in US has shown that the surge in obesity has reached pandemic proportions with 1.6 billion adults classified as overweight and a further 400 million adults classified as obese. ${ }^{1}$ That is why, American Heart Association, American College of Cardiology and The Obesity Society in November 2013, have emphasized that physicians should consider obesity a disease and more actively treat these patients for weight loss. ${ }^{2}$ Even though it has been generally accepted for a long time that obesity affects the somatic health, there has been studies coming up indicating that increased body weight in both male and female partners can affect reproductive health as well.

There are several postulated mechanisms of obesity affecting male fertility. Several studies showed that increased male basal metabolic index (BMI) is

1. Associate Professor, Department of Obstetrics and Gynecology, BIRDEM General Hospital, Dhaka, Bangladesh

2. Professor and Chief Consultant, Department of Obstetrics and Gynecology, BIRDEM General Hospital, Dhaka, Bangladesh

Address of correspondence:Tanzeem Sabina Chowdhury, Associate Professor, Obstetrics and Gynecology, BIRDEM general hospital, Dhaka, Bangladesh. Email- tanzeemsc@gmail.com. Mobile- 01713037853 
associated with reduced plasma concentrations of sex hormone binding globulin (SHBG) and testosterone with a concomitant rise in plasma concentration of estrogen. ${ }^{3}$ The aromatase cytochrome P450 enzyme, produced by adipose tissue and testicular Leydig cells is primarily responsible for aromatization that converts testosterone to estrogens. ${ }^{4}$ It has also been seen that obese men with type 2 diabetes can have secondary hypogonadism because of peripheral and central insulin resistance and the effect of proinflammatory cytokines (TNF \pm and IL-6) on Hypothalamo-pituitarygonodal (HPG) axis. ${ }^{5}$ Metabolic syndrome (MetS) is another disorder of energy utilization and storage which has also been associated with hypogonadism and erectile dysfunction (ED). ${ }^{6}$

Infertility in overweight or obese males may also be explained by leptin insensitivity. Leptinis a hormone produced primarily by fat cells and might damage sperm cells or the cells that produce them. An increase in leptin level alters the HPG axis and significantly decreases the production of testosterone from Leydig cells. ${ }^{7}$

Studies have also shown that oxidative stress increases with an increase in BMI, primarily due to an increase in seminal macrophage activation. This leads to decreased sperm motility, increased sperm DNA damage, decreased acrosome reaction and lower embryo implantation rates following IVF. ${ }^{8}$

So, this study was undertaken to investigate the impact of male obesity on the traditional sperm parameters mandated by the World Health Organization (WHO, 2010), namely sperm concentration, sperm motility and sperm morphology among the male partners of the infertile couples in Bangladesh. ${ }^{9}$

\section{Methods}

This hospital based cross sectional study was carried out in Infertility Management Center, a tertiary center for infertility management and IVF from August 2016 to October 2016. After fulfilling the inclusion and exclusion criteria men presented for infertility evaluation (consecutive)during this period were assessed by basic infertility evaluation measures including semen analysis and BMI calculation. Only male partners of couples trying to conceive for more than one year were included in this study. Those male partners who had chronic illness that may adversely affect the semen quality were excluded from this study.

Clinical and social demographic data were recorded in a predesigned sheet. Height and weight of the subjects were measured in the usual way. Body mass index (BMI) was calculated by using a simple calculation of a person's weight in kilograms divided by the square of his height in meters $\left(\mathrm{kg} / \mathrm{m}^{2}\right)$.

Participants were divided into three groups per WHO criteria-

Group I- BMI of $18.5-24.9 \mathrm{~kg} / \mathrm{m}^{2}$ - Normal weight

Group II- BMI of $25-29.9 \mathrm{~kg} / \mathrm{m}^{2}$ - Overweight

Group III- BMI of e"30 kg/m² - Obese

Each of the male partners was instructed to collect semen by masturbation in a clean, dry, wide mouthed and nontoxic container after 3 to 5 days of abstinence in a private room within the premises of the laboratory. The semen analysis was done by a single experienced technician to prevent inter technician variability. The sperm concentration was estimated by using the Makler counting chamber. Sperm morphology was assessed under light microscope by using semen smear. The semen parameters were interpreted normal or abnormal per WHO (2010) semen analysis reference values.

\begin{tabular}{ll}
\hline \multicolumn{2}{c}{ Semen analysis, WHO, 2010 } \\
\hline Volume & $1.5 \mathrm{ml}$ \\
$\mathrm{pH}$ & 7.2 \\
Sperm Concentration & $39 \mathrm{million} /$ ejaculate \\
Total sperm count & $15 \mathrm{million} / \mathrm{ml}$ \\
Total motility & $40 \%$ Progressively mobile- \\
& $32 \%$ \\
Vitality & $58 \%$ \\
Total sperm morphology & $4 \%$ (strict criteria) \\
\hline
\end{tabular}

Data collected for each individual subject were compiled and analyzed using computer-based software- Statistical Package for Social Science (SPSS) for Windows, version 23. 
Results:

Table-I

Demographic characteristics of the study population $(n=225)$

\begin{tabular}{lcc}
\hline Age (years) & Number & Percentage \\
\hline 21-30 years & 31 & 13.8 \\
31-40 years & 148 & 65.8 \\
41-50 years & 44 & 19.6 \\
>50 years & 02 & 0.9 \\
Educational status & & \\
Below SSC & 38 & 16.9 \\
SSC & 38 & 16.9 \\
HSC & 29 & 12.9 \\
Graduate & 40 & 17.8 \\
Post graduate & 80 & 35.6 \\
Occupational status & & \\
Service & 143 & 63.6 \\
Business & 80 & 35.6 \\
Student & 02 & 0.9 \\
Monthly income (Taka) & & \\
Less than 10000 & 28 & 12.4 \\
10000-25000 & 7 & 3.1 \\
25000-50000 & 166 & 73.8 \\
More than 50000 & 24 & 10.7 \\
\hline
\end{tabular}

Table I shows socio demographic characteristics of the study population; it was observed that almost two third $(65.8 \%)$ of the male partners belonged to age $31-40$ years. More than one third (35.6\%) male partners had completed post graduate education, 143 $(63.6 \%)$ male partners were service holder and $166(73.8 \%)$ of the male partners came from 25000 50000-taka monthly income family.

Table-II

Distribution of the study population according to $B M I$ of the subjects $(n=225)$

\begin{tabular}{lcc}
\hline BMl $\left(\mathrm{kg} / \mathrm{m}^{2}\right)$ & Number & Percentage \\
\hline Underweight $(<18.5)$ & 03 & 01.3 \\
Normal weight (18.5-24.9) & 82 & 36.4 \\
Over weight (25-29.9) & 100 & 44.4 \\
Obese $(\geq 30)$ & 40 & 17.8 \\
\hline
\end{tabular}

Table II shows body mass index of the study population. It was observed that majority $(44.4 \%)$ of the male partners were overweight $\left(25-29.9 \mathrm{~kg} / \mathrm{m}^{2}\right)$.

Table-III

Distribution of the study population according to total count of sperms $(n=225)$

\begin{tabular}{lcc}
\hline Total count(million/mL) & Number & Percentage \\
\hline$<15$ & 71 & 31.6 \\
$\geq 15$ & 154 & 68.4 \\
Mean $( \pm \mathrm{SD})$ & $54.4( \pm 53.2)$ & $0-280$ \\
\hline
\end{tabular}

Table III shows total count of spermatozoa the study in population; it was observed that more than two third $(68.4 \%$ ) male partners were total count $\geq 15$ million/ $\mathrm{mL}$. The mean total count was found $54.4 \pm 53.2$ million/ $\mathrm{mL}$ with range from 0 to 280 million $/ \mathrm{mL}$.

Table-IV

Distribution of the study population according to sperm active motility $(n=225)$

\begin{tabular}{lcc}
\hline Total active motility $(\%)$ & Number & Percentage \\
\hline$\leq 40$ & 131 & 58.2 \\
$>40$ & 94 & 41.8 \\
Mean $( \pm$ SD $)$ & $36.8( \pm 23.4)$ & $0-80$ \\
\hline
\end{tabular}

Table IV shows total active sperm motility of the study population; it was observed that majority (58.2\%) male partners had total active motility $\leq 40$ percent. The mean total active motility sperm was found to be $36.8 \pm 23.4$ percent with range from 0 to 80 percent.

Table-V

Distribution of the study population according to sperm morphology $(n=225)$

\begin{tabular}{lcc}
\hline Sperm morphology $(\%)$ & Number & Percentage \\
\hline$\leq 4.0$ & 25 & 11.1 \\
$>4.0$ & 200 & 88.9 \\
Mean $( \pm S D)$ & $42.0( \pm 22.1)$ & $0-80$ \\
\hline
\end{tabular}

Table $\mathrm{V}$ shows normal morphology of the study population; it was observed that majority $(88.9 \%)$ male partners had normal morphology $>4.0$ percent. The mean normal morphology of sperm was found $42.0 \pm 22.1$ percent with range from 0 to 80 percent. 


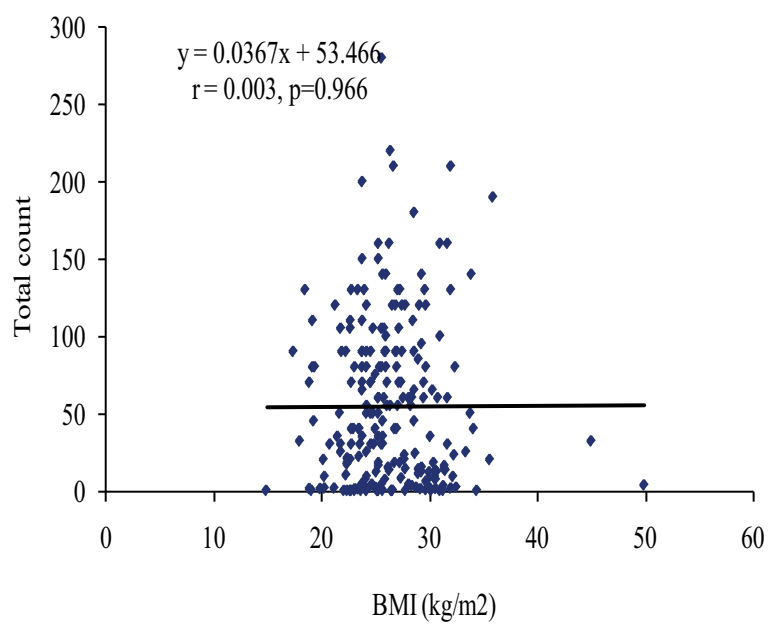

Fig.-1: Scatter diagram showing no correlation $(r=0.003 ; p=0.966)$ between BMI and total sperm count.

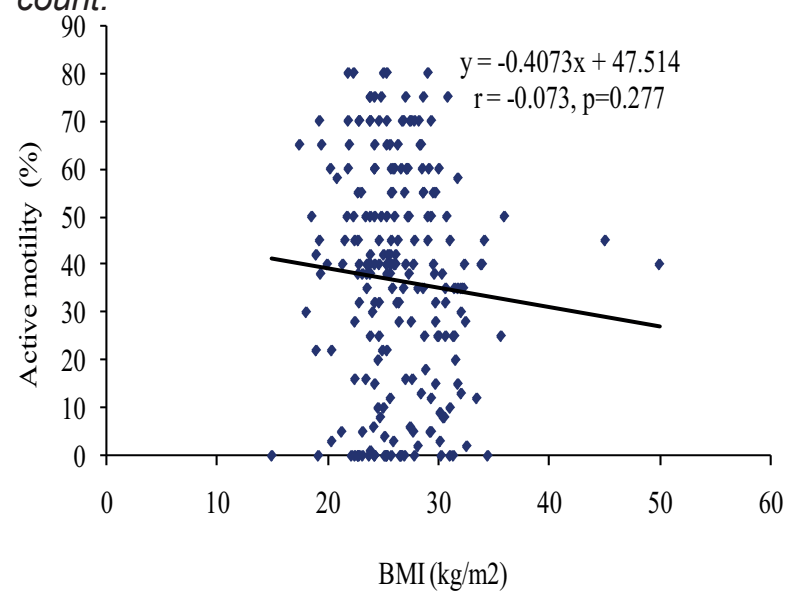

Fig.-2: Scatter diagram showing negative correlation $(r=-0.073 ; p=0.277)$ between $\mathrm{BMI}$ and total active motility of sperms.

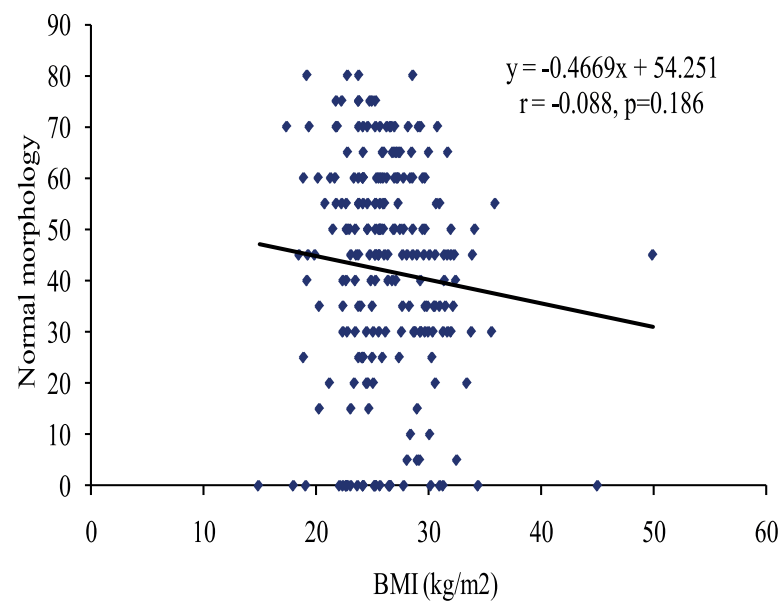

Fig.-3: Scatter diagram showing negative correlation ( $r=-0.088 ; p=0.186$ ) between BMI and normal morphology of sperms.
Regression analysis of different semen parameter shows that there is negative correlation between BMI and total actively motile sperm; and BMI and morphologically normal sperm (Fig. 1-3).

\section{Discussion}

It was observed in this study that amongst the partners of 225 infertile couples, almost two third $(65.8 \%)$ men belonged to age $31-40$ years. More than one third (35.6\%) men had completed post graduate education, $143(63.6 \%)$ men were service holder and $166(73.8 \%)$ of the men came from 26000-50000 taka monthly income family.

When body mass index (BMI) of the studypopulation was calculated, it was observed that majority (44.4\%) were overweight $\left(25-29.9 \mathrm{~kg} / \mathrm{m}^{2}\right)$. The mean BMI was found to be $26.33 \pm 4.18 \mathrm{~kg} / \mathrm{m}^{2}$ with range from 14.9 to $49.9 \mathrm{~kg} / \mathrm{m}^{2}$.

When total count of sperms was calculated in the studypopulation, it was observed that more than two third $(68.4 \%)$ male partners hadtotal count of $\geq 15 \mathrm{million} / \mathrm{mL}$. The mean total count was found to be $54.4 \pm 53.2 \mathrm{million} / \mathrm{mL}$ with range from 0 to 280 million $/ \mathrm{mL}$.

This study also showed that majority (58.2\%) the male partners had active motility of sperm of $\leq 40$ percent. The mean total active motility was found $36.8 \pm 23.4$ percent with range from 0 to 80 percent.

This study also showed that majority $(88.9 \%)$ of the patients were normal sperm morphologyof $>4.0$ percent. The mean normal morphology was found $42.0 \pm 22.1$ percent with range from 0 to 80 percent.

In this study, the scatter diagram showed no correlation $(r=0.003 ; p=0.966)$ between $\mathrm{BMI}$ and total sperm concentration. Two large cross sectional series done by Aggerholmet al. ${ }^{9}$ in 2008 among 1,989 European men and Duitset al. ${ }^{11}$ in 2010 on 1,401 men also showed no correlation between BMI and sperm concentration. This contrasts with a study done in Denmark in 2004 and another one in Netherlands in 2010 that have shown an inverse correlation between $\mathrm{BMI}$ and sperm concentration or total sperm count (TSC). ${ }^{12,13}$ Two meta-analysis were published. First one done by Mc Donald et al. ${ }^{14}$ in 2010 on pooled data from five studies including 4,853 men concluded that there was no evidence of an association between $\mathrm{BMI}$ and sperm concentration or TSC. However, the most recent collaborative meta-analysis in 2013 which was doneby Sermondade et al. ${ }^{15}$ on 13,077 men from 21 individual studies, showed a J-shaped association 
between BMI and abnormal sperm count: underweight was associated with an increased but non-significant risk of abnormal sperm count, whereas overweight and obese men had a significantly elevated risk of abnormal sperm count compared men with normal weight.

In our study, scatter diagram showed negative correlation between BMI with total active motility ( $r=$ 0.073; $p=0.277$ ). A similar study done by Hofny et al. ${ }^{16}$ in 2010 also found a significant negative correlation with sperm motility. Previously Hammoudet al. ${ }^{17}$ in 2008 also observed a significant increase in the prevalence of low progressively motile spermatozoa with increased BMI. On the other hand, studies done by Jensen et al. ${ }^{12}$ in 2004 and Martini et al. ${ }^{18}$ in 2010 failed to report any association between $\mathrm{BMI}$ and sperm total motility. Also, MacDonald et al. ${ }^{14}$ in 2010 in their meta-analysis, did not get a significant correlation between sperm motility and BMI.

In our study, scatter diagram showed negative correlation between BMI and normal morphology of sperm ( $r=-0.088 ; p=0.186)$. Results of sperm morphology studies have been variable due to differences in standards used for evaluation. ${ }^{17}$ Hammoud et al ${ }^{19}$ in 2008 and Chavarro et al. ${ }^{20}$ in 2010 found out no significant association between $\mathrm{BMI}$ and sperm morphology. MacDonald et $\mathrm{al}^{14}$. in his meta-analysis also found no correlation between BMI and sperm morphology. However, Hofnyet al. ${ }^{16}$ stated a significant positive correlation between $\mathrm{BMI}$ and abnormal sperm morphology. In 2008 in a study by Jensen ${ }^{12}$, all the semen samples from studied general population were investigated by a single investigator and showed no relationship between sperm morphology abnormalities and increasing BMI. More recently, a similar study was done by Belloc et al. ${ }^{21}$ in 2014 who reviewed data from 10,665 French men undergoing evaluation at a single fertility center. They observed a decreased ejaculate volume, sperm concentration, motility, and total count with extremely obese individuals (BMI $>40$ ), but the sperm morphology was unaffected.

Even though, there has been a global decline in the semen parameters in the last fifty year along with the concomitant rise in obesity, results of research studies correlating obesity and male infertility have been contradictory. To make the subject even more confusing, weight loss has not been shown to increase the fecundity in male partners. In fact, drastic weight loss specially following bariatric surgery has been shown to be severely detrimental for the sperm parameters. ${ }^{22}$

Even though BMI has been widely used in both clinical and research settings worldwide, it does not give any idea regarding the distribution of body fat like waist circumference or hip-to-waist ratio. So, further study should be done to evaluate the correlation of distribution of body fat to the different semen parameters.

Semen analysis is an integral part of fertility workup and considered to be the gold standard in evaluation of male partners of infertile couples, it does not analyze the functional capacity of the sperm or it's fertilization capacity. So, further study demonstrating the relationship between obesity and sperm function test like hemi-zona assay or zona binding test may be required in future.

This study was done on male partners of infertile couples during their initial fertility workup, so the incidence of abnormal sperm parameters is expected to be higher than in the general population. So, a bigger population based study is required to give a more accurate picture of the relationship between $\mathrm{BMI}$ and the semen parameters.

This study did not consider the lifestyle factors like smoking, alcohol intake or substance use that may affect the semen parameters. So, these are the limitations of this study.

So, future multi centered cohort studies are required in future to clarify the complex relationship between male obesity and infertility so that the male partners can be properly counselled regarding the beneficial effects of weight normalization by diet and exercise for improvement of their sperm parameters and subsequently fertility status.

\section{References:}

1. Vermeulen A, Kaufman JM, Deslypere JP, Thomas G. Attenuated luteinizing hormone (LH) pulse amplitude but normal LH pulse frequency, and its relation to plasma androgens in hypogonadism of obese men. $J$ ClinEndocrinolMetab. 1993;76:1140-1146

2. AHA/ACC/TOS Guideline 2013 for the Management of Overweight and Obesity in Adults. A Report of the American College of Cardiology/American Heart Association Task 
Force on Practice Guidelines and The Obesity http://dx.doi.org/10.1161/01.cir.0000437739. 71477.ee. Circulation. 2014;129:S102S138. Originally published November 12, 2013

3. Nguyen DM, El-Serag HB. Review The epidemiology of obesity. Gastroenterol Clin North Am. 2010;39:1-7.

4. Phillips KP, Tanphaichitr N. Mechanisms of obesity-induced male infertility. Expert Rev EndocrinolMetab. 2010; 5: 229-251.

5. Bhasin S, Cunningham GR, Hayes FJ, Matsumoto AM, Snyder PJ, Swerdloff RS. Testosterone therapy in men with androgen deficiency syndromes: an Endocrine Society clinical practice guidelinase. $J$ ClinEndocrinolMetab. 2010;95:2536-2559.

6. Traish AM, Guay A, Feeley R, Saad F. The dark side of testosterone deficiency: I. Metabolic syndrome and erectile dysfunction. J Androl. 2009;30:10-22

7. Caprio M, Isidori AM, Carta AR, Moretti C, Dufau $\mathrm{ML}$, Fabbri A. Expression of functional leptin receptors in rodent Leydig cells. Endocrinology. 1999; 140: 4939-4947.

8. Palmer NO, Bakos HW, Fullston T, Lane M. Impact of obesity on male fertility, sperm function and molecular composition. Spermatogenesis. 2012; 2: 253-263.

9. Aggerholm AS, ThulstrupAM, Toft G, RamlauHansen $\mathrm{CH}$, Bonde JP. Is overweight a risk factor for reduced semen quality and altered serum sex hormone profile? FertilSteril. 2008;90:619-626.

10. Duits $F H$, van Wely $M$, van der Veen $F$, Gianotten J. Healthy overweight male partners of subfertile couples should not worry about their semen quality. FertilSteril. 2010;94:1356-1359.

11. Jensen TK, Andersson AM, Jørgensen N, Andersen AG, Carlsen E, Petersen JH, SkakkebaekNE.Body mass index in relation to semen quality and reproductive hormones among 1,558 Danish men.FertilSteril. 2004 Oct; 82(4):863-70.

12. Paasch U, Grunewald S, Kratzsch J, GlanderHJ.Obesity and age affect male fertility potential.FertilSteril2010 Dec; 94(7):2898-90
13. MacDonald AA, Herbison GP, Showell M, Farquhar CM.The impact of body mass index on semen parameters and reproductive hormones in human males: a systematic review with meta-analysis. Hum Reprod Update. 2010 May-Jun; 16(3):293-311.

14. N Sermondade, C Faure, L Fezeu, A, G.Shayeb, $\mathrm{J} P$ Bonde. BMI in relation to sperm count: an updated systematic review and collaborative meta-analysis. Hum Reprod Update. 2013 May; 19(3): 221-231.(

15. Hofny ER, Ali ME, Abdel-Hafez HZ, Kamal Eel D, Mohamed EE, Abd El-Azeem HG, Mostafa T. Semen parameters and hormonal profile in obese fertile and infertile males. FertilSteril 2010; 94:581-584.

16. Hammoud AO, Wilde N, Gibson M, Parks A, Carrell DT, Meikle AW. Male obesity and alteration in sperm parameters. FertilSteril 2008b; 90:2222-2225.

17. Martini AC, Tissera A, Estofan D, Molina RI, Mangeaud A, de Cuneo MF, Ruiz RD. Overweight and( seminal quality: a study of 794 patients. FertilSteril2010; 94:1739-1743.

18. Hammoud AO, Gibson M, Peterson CM, Meikle AW, Carrell DT. Impact of male obesity on infertility: a critical review of the current literature. FertilSteril2008a; 90:897-904.

19. Chavarro JE, Toth TL, Wright DL, Meeker JD, Hauser R. Body mass index in relation to semen quality, sperm DNA integrity, and serum reproductive hormone levels among men attending an infertility clinic. FertilSteril2010; 93:2222-2231.

20. Belloc S, Cohen-Bacrie M, Amar E, Izard V, Benkhalifa M, Dalleac A, et al. High body mass index has a deleterious effect on semen parameters except ( morphology: results from a large cohort study. FertilSteril2014;102:126873

21. Sermondade N, Massin N, Boitrelle F, Pfeffer J, Eustache F, Sifer C, Czernichow S, Levy R. Sperm parameters and male fertility after bariatric surgery: three case series. Reprod Biomed Online. 2012b;24:206-210. 